\title{
Intrathoracic Kaposi's sarcoma in patients with AIDS
}

\author{
Jacques Cadranel, Charles Mayaud
}

In early 1981 the acquired immunodeficiency syndrome (AIDS) was initially recognised from the outbreak of Kaposi's sarcoma and Pneumocystis carinii pneumonia among young, previously healthy homosexual men. ${ }^{12}$ The incidence of Kaposi's sarcoma as an inaugurating event has decreased regularly since the mid 1980 s from between $35-40 \%$ to less than $15 \%$ of all cases of AIDS presently reported in Europe and the USA ${ }^{134}$; Kaposi's sarcoma, however, still remains the most frequent cause of pulmonary localisation of AIDS associated malignancies, and the prognosis of Kaposi's sarcoma is related in part to visceral involvement, particularly the lung. ${ }^{125}$ Although our knowledge of this disease remains incomplete, several recent studies have considerably advanced our understanding of the pathogenesis, diagnosis and, to a lesser extent, the treatment of Kaposi's sarcoma, particularly in cases of visceral involvement. ${ }^{1-46}$ The purpose of this review is threefold: firstly, to summarise recent advances concerning the pathogenesis of Kaposi's sarcoma; secondly, to review briefly the pathological and clinical features of the disease; and finally, to describe current approaches to its diagnosis and treatment. Although all forms are discussed, this review will concentrate on intrathoracic $\mathrm{Ka}$ posi's sarcoma. There are a number of recent reviews available which emphasise other aspects of the disease. ${ }^{346}$

\section{Pathogenesis of Kaposi's sarcoma: an unresolved debate}

The use of new technology in investigating the cellular and molecular changes has resulted in better understanding of the pathogenesis of Kaposi's sarcoma, but numerous questions remain unanswered.

\author{
Service de \\ Pneumologie et de \\ Réanimation \\ Respiratoire, \\ Hôpital Tenon, \\ Paris 75020, France \\ J Cadranel \\ C Mayaud \\ Reprint requests to: \\ Dr J Cadranel.
} cells" of Kaposi's sarcoma lesions has long been a point of controversy and different cell types have, in turn, been suspected. Recent data, however, indicate that the original cell could well be a multipotential cell of mesenchymal derivation. ${ }^{346}$ This hypothesis is based on phenotypical and cytochemical studies per- formed on spindle cells obtained from long term culture of AIDS-associated Kaposi's sarcoma tissue.

\section{AETIOLOGICAL FACTORS}

The aetiology of Kaposi's sarcoma has not been precisely established, even if the most widely accepted view is a multifactorial one. Genetic, endocrinological, and environmental factors, as well as infectious agents, have been suspected in the development of Kaposi's sarcoma. Although the major histocompatibility antigens, HLA-DR5 and HLA-DR2, were reported with increased frequency both in classical Kaposi's sarcoma and in AIDS-associated Kaposi's sarcoma at the beginning of the AIDS epidemic, these data were not confirmed in HLA typing in subsequent later series of AIDS-associated Kaposi's sarcoma ${ }^{67}$ The human immunodeficiency virus was the first infectious agent proposed as an aetiological factor in the Kaposi's sarcoma epidemic. The HIV genome has not yet been detected in Kaposi's sarcoma lesions, but this does not rule out a possible indirect role for HIV; it has recently been shown, for example, that mice transfected by the HIVtat gene developed clinical and histological Kaposi's sarcoma-like tumours. In this model the HIV genome is present on epidermal cells but absent in dermal tumours, indicating that HIV could act in an indirect way to cause the proliferation of the endothelial, lymphatic, or multipotential cells found in Kaposi's sarcoma lesions. ${ }^{89}$ Another possible infectious origin is suggested by a number of epidemiological studies which have led to the theory of a possible sexually transmitted co-agent. ${ }^{346}$ None of the suspected causative agents (CMV, EBV, HPV-16, HTLV-I, HBV, Mycoplasma incognito) has yet been proved to be involved. Several other data also argue against this hypothesis or limit its scope: firstly, no one causative agent has been regularly isolated in Kaposi's sarcoma tissue; secondly, this theory of sexual transmission does not explain the male predominance in African patients with AIDSassociated Kaposi's sarcoma in whom HIV has been transmitted through heterosexual contact, or the development of Kaposi's sarcoma in non-AIDS immunocompromised hosts. 
Finally, some investigators have recently proposed a role for a different subtype of HIV or a defective form of HIV because of the presence of antibodies against gp41 and nef in the serum of an HIV seronegative patient with Kaposi's sarcoma. ${ }^{6}$

IMMUNE IMBALANCE AND THE HISTOGENESIS OF KAPOSI'S SARCOMA

It has generally been accepted that immune deficiency was a prerequisite for the development of Kaposi's sarcoma, but at the present time it seems more likely that Kaposi's sarcoma in AIDS results from an immune imbalance rather than a true immune deficiency. Studies in classical and endemic Kaposi's sarcoma show no detectable immune deficiency. ${ }^{34}$ Similarly, a small number of HIV seropositive patients develop Kaposi's sarcoma without clinical or biological data, indicative of immune deficiency. ${ }^{10}$ It has recently been suggested that Kaposi's sarcoma may develop in a subject with a particular genetic background who is exposed to numerous infectious agents and environmental factors which, at a given point, trigger the immune and inflammatory response. Through the effects of mediators such as interleukins 1 and 6, fibroblast growth factor, and oncostatin $\mathrm{M}^{11-13}$ and/or viral proteins (tatprotein), the immune activation may initiate the proliferation of mesenchymal cells observed in Kaposi's sarcoma lesions. ${ }^{89}$ As a result of the effects of their extracellular products, these activated AIDS-associated Kaposi's sarcoma cells may maintain their own proliferation by an autocrine and paracrine pathway leading to the proliferation of endothelial cells, smooth muscle cells, and fibroblasts which histologically characterise Kaposi's sarcoma. ${ }^{14}$

\section{Clinical and radiological features of intrathoracic Kaposi's sarcoma}

In Europe and the USA epidemic Kaposi's sarcoma occurs in patients of all ages, is mainly found in HIV-infected homosexual or bisexual men, and is observed in less than $10 \%$ of patients in other groups at risk for HIV infection. ${ }^{346}$ In Africa the predominance of Kaposi's sarcoma in men is less pronounced than in Europe and the USA. ${ }^{46}$ Epidemic Kaposi's sarcoma mainly involves the skin, particularly the lower limbs. The lesions vary in colour from red to purple and in appearance from macular, papular, or nodular lesions to plaques. These lesions, frequently localised at the onset of Kaposi's sarcoma, usually progress in a multifocal and widespread distribution with possible later mucosal and visceral involvement. Virtually all organs may be involved, but lymph nodes, the gastrointestinal tract, and the lungs are the commonest sites. ${ }^{15-17}$

\section{FREQUENCY}

Although there has been a steady decrease in the proportion of patients with Kaposi's sarcoma among those infected with HIV in recent years, it is still the foremost cause of lung tumours in patients with AIDS $^{12}$ and the third and fourth cause of all pulmonary disease in HIV-infected Africans and Europeans respectively. ${ }^{1218}$ The frequency of intrathoracic Kaposi's sarcoma has been appreciated in various situations. In HIV-infected patients, what-걱 ever the risk factor, Kaposi's sarcoma was ato the origin of $8-18 \%$ of lung disorders ${ }^{2519-22}$ and from $10-45 \%$ of pleural effusions. ${ }^{23}$ In patients

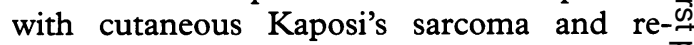
spiratory symptoms it was identified as the cause of respiratory disease in $18-40 \%$ of $\frac{\overline{\bar{c}}}{\mathrm{n}}$ cases. ${ }^{1516182224}$ In patients with cutaneous $\mathrm{Ka}-\frac{\mathrm{D}}{\overline{\mathrm{D}}}$ posi's sarcoma but no respiratory symptoms it was present in 6-20\% of cases, ${ }^{152526}$ while in कै those with cutaneous lesions it was the cause $\vec{\circ}$ of virtually all bilateral pleural effusions. ${ }^{27} \mathrm{Fi}-$ nally, in patients with cutaneous Kaposi's sarcoma intrathoracic Kaposi's sarcoma was found $\vec{f}$ at necropsy in $38-75 \%$ of cases. ${ }^{12}$ Almost all intrathoracic structures may be involved - that. is, lung parenchyma, airways, and pleura and, to a lesser extent, the lymph nodes, pericardium, and heart. ${ }^{12}$ Macroscopic ex-윽 amination of the lung at necropsy reveals bright red or violaceous haemorrhagic nodules which $\frac{}{2}$ may coalesce into larger masses or cause septal” angiomatous infiltration; the pleural and the $\vec{\bullet}$ intrathoracic lymph nodes are involved in morec than $50 \%$ of cases. ${ }^{12}$ Microscopic findings at necropsy show that the lung lesions have a? predominantly peribronchial and perivascular distribution and, in some places, invade theo bronchial and vascular walls. ${ }^{12}$

\section{CLINICAL MANIFESTATIONS}

In patients with cutaneous Kaposi's sarcomao the discrepancy between the low frequency of respiratory symptoms due to Kaposi's sarcomao and the high frequency of respiratory Kaposi's sarcoma found at necropsy indicates that intrathoracic Kaposi's sarcoma is insidious. in most cases. Except in Africa ${ }^{18}$ patients are homosexual or bisexual men in $95 \%$ of cases and have had progressive, previously treated,? cutaneous lesions in more than $50 \%$ of cases. ${ }^{15162628}$ However, simultaneous cutaneous Kaposi's sarcoma may be absent inN $5-23 \%$ of patients with symptomatic pulmonary Kaposi's sarcoma. ${ }^{162829}$ Other visceral localisation is not unusual and gastrointestina ${ }^{\omega}$ tract involvement has been observed in at least $27 \%$ of cases from a homogeneous series of patients with pulmonary Kaposi's sarcoma. ${ }^{2 \& ?}$ Clinical and/or biological expression of im-0 mune deficiency is common. At least one opportunistic infection has occurred in $35-79 \%$ of patients before the diagnosis of their pulmonary尽 Kaposi's sarcoma. ${ }^{1517242528}$ Mean CD4 celp counts have been 77,96 , and $170 / \mu \mathrm{l}$ in threen recent series. ${ }^{242830}$ However, pulmonary Ka-O posi's sarcoma has been reported in patientso with more than $400 \mathrm{CD} 4$ cells $/ \mu .^{2428}$ Pro gressive dyspnoea is observed in $83-100 \%$ of cases ${ }^{151718242528}$; mean $\mathrm{PaO}_{2}$ was $8 \cdot 0,8 \cdot 0,9 \cdot 0$ and $10.2 \mathrm{kPa}$ at presentation in four recently published series. ${ }^{15182428}$ Furthermore, acute respiratory failure requiring mechanical ventilation has occurred in patients with no 
pulmonary or cardiovascular disease other than Kaposi's sarcoma. ${ }^{1631}$ Non-productive cough is present in $67-100 \%$ of cases and is associated with mild haemoptysis in about one third. ${ }^{1517182224252829}$ Lower thoracic pain attributed to pleural effusion is reported in $17-47 \%$ of patients. ${ }^{1517242528}$ High fever $\left(\geqslant 38.5^{\circ} \mathrm{C}\right)$ on presentation is found in $30-53 \%$ of patients with pulmonary Kaposi's sarco$\mathrm{ma}^{15-172428}$; in most of these it is related to concomitant pulmonary or extrapulmonary bacterial and/or opportunistic infection. However, aggressive pulmonary Kaposi's sarcoma itself, or in association with multicentric Castleman's disease, has also been reported as the cause of such fever. ${ }^{283233}$ Physical examination of the thorax is usually normal or indicates non-specific signs such as crackles, wheeze, or stridor in patients with Kaposi's sarcoma of the upper respiratory tract. ${ }^{12}$

\section{CHEST RADIOGRAPHY AND COMPUTED TOMOGRAPHY}

Although chest radiographs of patients with intrathoracic Kaposi's sarcoma may be normal in 5-20\% of cases, ${ }^{15634-38}$ they commonly show diffuse parenchymal abnormalities in two major patterns which correlate well with pathological findings. The first is a predominance of perihilar linear densities that follow septal lines and are observed in about $40 \%$ of cases; the second is a predominance of a single nodular opacity or of multiple nodular opacities with no preferential distribution which may sometimes coalesce and are also seen in about $40 \%$ of cases. ${ }^{152634-38}$ The association of both abnormalities found in nearly $70 \%$ of patients is highly suggestive of pulmonary Kaposi's sarcoma. Other parenchymal abnormalities such as segmental or lobar, alveolar or interstitial infiltrates and atelectasis are less common findings on radiography. The frequency of pleural and intrathoracic lymph node involvement on the radiograph has varied widely. Pleural effusions have been observed in 7-50\% of chest radiographs. ${ }^{152634-38}$ When present they are usually large, bilateral, and associated with parenchymal lesions ${ }^{15-17252738}$; these characteristics are highly suggestive of Kaposi's sarcoma. ${ }^{27} 3439$ Intrathoracic lymph nodes visible on radiography have been reported in $8-46 \%$ of cases but their Kaposi's sarcoma origin has seldom been verified by histological examination. ${ }^{15192627353839}$

Few studies have been published about the computed tomographic (CT) examination of patients with proven or highly probable intrathoracic Kaposi's sarcoma and no associated opportunistic infection. The respective frequencies of pulmonary nodules, peribronchovascular thickening, pleural effusions, and tumour masses has varied from $31-100 \%$, $35-87 \%, 55-70 \%$, and $15-56 \%$, respectively, in recent series of patients evaluated by computed tomographic scanning. ${ }^{34373940}$ In the largest (unpublished) series evaluating CT scanning in 61 patients with intrathoracic $\mathrm{Ka}$ posi's sarcoma the association of two or more of these abnormalities was found in $75 \%$ of cases. In the same series mediastinal lymph nodes were visible in $43 \%$ of cases but were enlarged in less than one third. Other abnormalities such as septal lines and pericardial effusion are still less frequent; ground glass opacities are very unusual and, if present, are associated with alveolar haemorrhage.

\section{FIBREOPTIC BRONCHOSCOPY}

There are two main reasons why bronchoscopy is the gold standard for the diagnosis of intrathoracic Kaposi's sarcoma in cases with visible endobronchial lesions: (1) bronchial biopsy samples of Kaposi's sarcoma lesions have a poor diagnostic yield and cannot be repeated indefinitely ${ }^{12}$; and (2) in most cases the macroscopic appearance of endobronchial lesions is highly suggestive of Kaposi's sarcoma and their presence has been found to be predictive of parenchymal Kaposi's sarcoma in at least one necroscopic study. ${ }^{17}$ Consequently, in patients with known histologically proven Kaposi's sarcoma cutaneous lesions, suggestive endobronchial lesions are considered to be sufficient for diagnosis. ${ }^{121}$ Endobronchial Kaposi's sarcoma lesions typically consist of single or multiple, red or purple, flat or raised, non-stenotic lesions that tend to predominate in the trachea and at segmental junctions in the main bronchi. ${ }^{12}$ Less frequently macroscopic lesions are distal and stenotic, although complete obstruction by intraluminal tumour is very uncommon. ${ }^{12}$ Endobronchial lesions have been found in $4-25 \%$ of patients with cutaneous Kaposi's sarcoma and respiratory symptoms, whether they are related to intrathoracic $\mathrm{Ka}$ posi's sarcoma or not. ${ }^{15242542}$ They were present in more than $70 \%(35-95 \%)$ of patients receiving chemotherapy for symptomatic intrathoracic Kaposi's sarcoma. ${ }^{1524252842}$ Although generally safe, bronchial or transbronchial biopsy samples have a poor diagnostic yield (less than $30 \%$ ) but have only been evaluated in small series of patients (5-27 patients). ${ }^{2}$ Since an associated infection was reported in $17-27 \%$ of patients evaluated for symptomatic intrathoracic Kaposi's sarcoma, a further role for bronchoscopy in these patients is its ability to demonstrate the absence of any such pulmonary infection before starting chemotherapy. ${ }^{2151822252829}$ In this context, the frequency of bacterial colonisation or infection due to Staphylococcus aureus and Pseudomonas aeruginosa should be stressed. ${ }^{18}$ Finally, some studies of bronchoalveolar lavage in patients with pulmonary Kaposi's sarcoma without pulmonary infection have shown a high frequency of alveolar haemorrhage ${ }^{31}$; other series have failed to confirm this finding. ${ }^{2943}$

\section{PULMONARY FUNCTION TESTS}

The abnormalities of pulmonary function tests observed in patients with pulmonary Kaposi's sarcoma are usually non-specific and consist of a reduction in the forced expiratory volume in one second/forced vital capacity and a low diffusing capacity (TLCO); although less frequent, a decrease in vital capacity has also been 
reported. ${ }^{1718222944}$ The severity of the airways obstruction has been correlated to the widespread finding of radiological abnormalities and endobronchial Kaposi's sarcoma lesions. ${ }^{229} \mathrm{Fi}$ nally, it has also been suggested that a normal TLCO and an improvement in the alveolararterial oxygen gradient during exercise were more likely to be found in patients with pulmonary Kaposi's sarcoma than in those with opportunistic pneumonia. ${ }^{24}$

\section{ISOTOPE TESTS}

Unlike pulmonary infections or lymphoid processes in HIV-infected patients, pulmonary Kaposi's sarcoma does not fix gallium so, in an AIDS patient with or without cutaneous Kaposi's sarcoma, interstitial and/or nodular changes on the chest radiograph that do not label with gallium strongly suggest pulmonary Kaposi's sarcoma. On the other hand, the presence of focal gallium uptake in lungs or mediastinal lymph nodes in patients with Kaposi's sarcoma is highly suggestive of concomitant infection and/or lymphoma. ${ }^{45-47}$ In addition, Kaposi's sarcoma, but not infectious lesions, has been shown to fix thallium, ${ }^{48}$ other radionuclides such as technetium pertechnetate-99 and pooled human immunoglobulin labelled with indium-111 have also been studied. ${ }^{45} 49$ The clinical interest of these tests, however, requires further investigation. ${ }^{45}$

\section{MAGNETIC RESONANCE IMAGING}

In a recent study, spin echo $T 1$ enhancement after gadolinium associated with a marked reduction of the second echo of the spin-echo $\mathrm{T} 2$ in the pathological areas were observed in patients with pulmonary Kaposi's sarcoma but not in patients with Pneumocystis carinii pneumonia. ${ }^{50}$ The angiomatous and fibrous com- ponents of Kaposi's sarcoma would account for this finding.

\section{Diagnostic approaches to intrathoracic Kaposi's sarcoma (figure)}

Whatever their suggestive diagnostic value, no clinical or radiological data allow the clinician to make a firm diagnosis of intrathoracic Kaposi's sarcoma. In most cases fibreoptic os bronchoscopy showing suggestive lesions suffices for this diagnosis. In the absence of such lesions thoracoscopy, mediastinoscopy, or thoracotomy are needed, depending on the $\triangle$ radiological appearances of the intrathoracic of involvement.

\section{DIAGNOSTIC APPROACH IN ASYMPTOMATIC \\ PATIENTS}

In patients with known cutaneous Kaposi's of sarcoma but without pulmonary symptoms, systematic chest radiography may reveal abnormalities. From the therapeutic point of view the requirement is not to diagnose Kaposi's sarcoma but to identify infection. In cases where non-invasive investigations such as CT scans, gallium scans, pulmonary function tests, and plasma levels of lactate dehydrogenase $(\mathrm{LDH})$ are all in agreement with a diagnosis of Kaposi's sarcoma, fibreoptic bronchoscopy must be the next step. Either endobronchial Kaposi's sarcoma lesions are seen and the diagnosis is complete, or further radiological and endoscopic examinations must be repeated regularly unless cytotoxic treatment is given for respiratory symptoms. The appearance of endobronchial Kaposi's sarcoma lesions will confirm retrospectively the diagnosis in most cases. When results from non-invasive investigations are conflicting, fibreoptic bronchoscopy with bronchoalveolar lavage is necessary. In cases

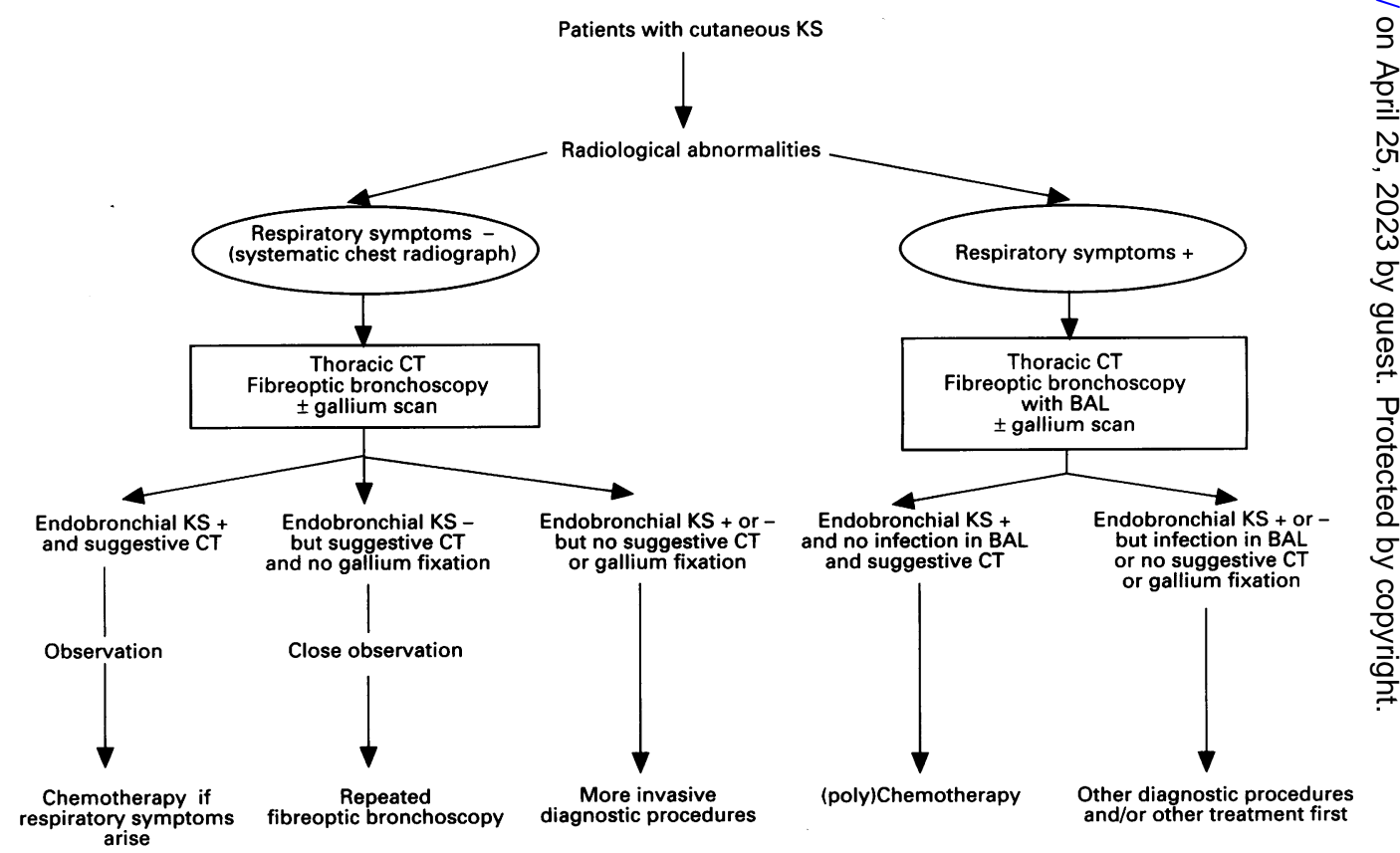

Algorithm for clinical approach to HIV-infected patients suspected of having intrathoracic Kaposis sarcoma. 
where this does not find pathogens or Kaposi's sarcoma other invasive procedures may be undertaken.

\section{DIAGNOSTIC APPROACH IN SYMPTOMATIC PATIENTS}

In most cases clinical data, particularly extensive cutaneous Kaposi's sarcoma, and CT data, particularly a combination of multiple nodules, peribronchovascular thickening and bilateral pleural effusions, are highly suggestive of bronchopulmonary Kaposi's sarcoma. In these patients fibreoptic bronchoscopy will reveal obvious endobronchial lesions and bronchoalveolar lavage would exclude the possibility of associated infection. This is enough to justify starting cytotoxic chemotherapy. In cases with a negative result on bronchoscopy the macroscopic Kaposi's sarcoma lesions necessary to start chemotherapy must be sought by thoracoscopy or thoracotomy.

There are three particular situations which need additional investigation even when endobronchial Kaposi's sarcoma lesions are visible.

\section{Patients with high fever $\left(\geqslant 38 \cdot 5^{\circ} \mathrm{C}\right.$ )}

The fever may be caused by Kaposi's sarcoma or by an infection. Bronchoalveolar lavage and protected bronchial brushing are justified, particularly in the presence of ground glass opacities on CT scanning ${ }^{39}$ and/or high gallium uptake ${ }^{45}$ and/or an increase in plasma levels of $\mathrm{LDH}^{12}$

\section{Patients with enlarged mediastinal lymphadenopathy}

In this situation mediastinoscopy is required, particularly in cases where the CT scan is suggestive of a necrotic process ${ }^{39}$ and/or where there is a high gallium uptake, in order to diagnose other possible causes such as tuberculosis, cryptococcosis, histoplasmosis, or lymphoma. ${ }^{28}$

\section{Patients with isolated pleural effusions}

Kaposi's sarcoma is the cause in half the homosexual patients. The other causes include tuberculosis, bacterial infection or, more rarely, opportunistic infection (cryptococcosis, pneumocystosis, leishmaniasis) or tumour (carcinoma, lymphoma). ${ }^{2327}$ In a recent series of 37 cases of pleural effusion with an identified cause an analysis of the diagnostic value of clinical and/or radiological data was made in an attempt to differentiate Kaposi's sarcomarelated pleural effusions from those of infectious origin. ${ }^{27}$ Clinically the presence of cutaneous Kaposi's sarcoma, no fever, and the progressive onset of symptoms had a positive predictive value for Kaposi's sarcoma-related pleural effusion of $80 \%, 80 \%$, and $83 \%$, respectively, while their absence had a negative predictive value of more than $92 \%$. Radiologically the presence of bilateral effusions and the association of lung opacities had a positive predictive value of $95 \%$ and $90 \%$, respectively, whilst their absence had a negative predictive value nearing $100 \% .^{27}$ Macroscopically, blood-stained or chylous pleural effusion is suggestive of Kaposi's sarcoma. ${ }^{15162527}$ In contrast, cells and tissue obtained by pleural fluid aspiration and biopsy are no help in establishing a diagnosis of Kaposi's sarcoma. ${ }^{215162527}$ The final diagnostic strategy differs in two sets of circumstances. In the first, clinical and radiological data are suggestive and Kaposi's sarcoma endobronchial lesions are seen: thoracoscopy is unnecessary to confirm the origin of the effusion. In the second, clinical and radiological data are conflicting and/or no Kaposi's sarcoma endobronchial lesions are seen: visualisation of pleural or parenchymatous Kaposi's sarcoma lesions by thoracoscopy or thoracotomy is required for diagnosis.

\section{Treatment of intrathoracic Kaposi's sarcoma}

Indications for treatment are based on the following findings: (1) dyspnoea due to progressive parenchymal disease, large pleural effusions, or airways obstruction by tumour is the major symptom of intrathoracic Kaposi's sarcoma which can affect the quality of life $\mathrm{e}^{12}$; (2) death usually results from the extension of Kaposi's sarcoma itself or from associated infection $^{242842}$; (3) survival of untreated symptomatic patients is usually less than four months ${ }^{161726}$ although asymptomatic patients may survive for up to several years ${ }^{12}$; (4) improvement in symptoms, the quality of life, and survival have all recently been reported in symptomatic patients treated by multidrug chemotherapy ${ }^{151624283036425152}$ but half these patients died of drug-induced complications. ${ }^{1524283036425152}$ Because of the risks and limitations of treatment it should be reserved for symptomatic patients, the objective being more to improve short term comfort than to increase long term survival. Modalities for treatment include prophylaxis and immune response modifiers, as well as chemotherapy, radiotherapy, and best supportive care. ${ }^{12}$

\section{PROPHYLAXIS, ANTIRETROVIRAL AGENTS AND} IMMUNE RESPONSE MODIFIERS

Since patients with intrathoracic Kaposi's sarcoma usually have less than 200 CD4 cells/ $\mu \mathrm{l}$ and/or prior opportunistic infections, they require combined prophylaxis and antiretroviral therapy. ${ }^{53}$ Since the efficacy of and tolerance to trimethoprim-sulphamethoxazole (TMP-SMZ) (400-80 mg daily) has been demonstrated in groups of patients with Kaposi's sarcoma, it should be given as the first line prophylactic drug against Pneumocystis carinii pneumonia. ${ }^{54}$ In addition, TMP-SMZ has a protective effect against toxoplasmosis and certain bacterial infections. ${ }^{545}$ If TMP-SMZ is contraindicated, dapsone should be preferred to aerosolised pentamidine because of the unforeseeable bioavailability of the latter in patients with bronchopulmonary Kaposi's sar- 
Results obtained with monochemotherapy or polychemotherapy in the treatment of patients with intrathoracic Kaposi's sarcoma

\begin{tabular}{llll}
\hline $\begin{array}{l}\text { Treatment } \\
\text { Drug[dose] interval }\end{array}$ & $\begin{array}{l}\text { No. of } \\
\text { patients* }\end{array}$ & $\begin{array}{l}\text { Response } \\
\text { (\%) }\end{array}$ & $\begin{array}{l}\text { Survival } \\
\text { (months) }\end{array}$ \\
\hline A[40]B[10]Vb[6] every month ${ }^{15}$ & $19(19)$ & $\mathrm{NR}$ & 6 \\
A[10-20]B[10]V[1,4] or BV or A[20] & $20(20)$ & 60 & 8 \\
every two weeks & & & \\
A[40]B[15]V[1,4] every three weeks ${ }^{28}$ & $30(30)$ & 40 & 6 \\
A[40]B[10]Vb[6] every month & $19(\mathrm{NR})$ & 74 & $\mathrm{NR}$ \\
A[20]Vb[4]B[15] at day 1, Act[1]V[1,4] & $18(4)$ & 93 & $\mathrm{NR}$ \\
Dac[375] at day 8, B[15] at day 15, & & & \\
every month & & & \\
A[10]B[10]V[1,4] every two weeks & $21(7)$ & 90 & 8 \\
A[20]B[10]V[1,4] every two weeks & $12(2)$ & 58 & 8 \\
A[20]B[10]V[2] every two weeks & $24(8)$ & 88 & 9 \\
A[20] every two weeks & $29(7)$ & 48 & 4
\end{tabular}

* Numbers in parentheses are numbers of patients with intrathoracic Kaposi's sarcoma; NR= not reported.

$\mathrm{A}=$ adriamycin, $\mathbf{B}=$ bleomycin, $\mathrm{V}=$ vincristine, $\mathrm{Vb}=$ vinblastine, $\mathrm{Act}=$ actinomycin $\mathrm{D}, \mathrm{Dac}=$ dacarbazine. For each drug the dose per course expressed in $\mathrm{mg} / \mathrm{m}^{2}$ is indicated in square brackets. therapy is 6-9 months even though survival of more than two years has been reported. ${ }^{151624283036425152}$ (3) There are prognostic factors for poor survival. Multivariate analysis of results from at least three series indicates that haemoglobin values $<10 \mathrm{~g} / \mathrm{dl}$, leucopenia $<1500 / \mu \mathrm{l}, \mathrm{CD} 4$ count $<100 \mu \mathrm{l}$, and

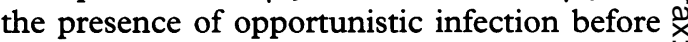
chemotherapy are all predictors of rapid evolution to death..$^{243042}$ In some series certain $\stackrel{\vec{P}}{+}$ factors such as the presence of bilateral effusions, Karnofsky index of $<70 \%$, the absence $\frac{\bar{T}}{\bar{n}}$ of response on radiography, and the absence of $\frac{\omega}{\bar{D}}$

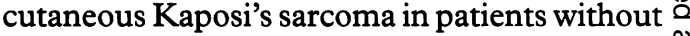
previous chemotherapy allowed prediction of $\%$ a shorter survival. ${ }^{24283042}$ Finally, in one series $\overrightarrow{0}$ previous treatment of cutaneous Kaposi's sar- $\vec{\partial}$ coma by $\alpha-\mathrm{INF}$ and/or monochemotherapy, the $\bar{\omega}$ degree of hypoxaemia, the platelet count before chemotherapy, and the degree of improvement $x$ of $\mathrm{PaO}_{2}$ after the first course of chemotherapy were not statistically related to survival. ${ }^{28}$ These factors were not evaluated in other series. (4) All patients experience some side effects. Fever 음 and shivering related to intravenous bleomycin $\rightarrow$ occurs in some patients but may be countered $\rightarrow$ by paracetamol. Peripheral neuropathy and cardiomyopathy are observed in patients re- $\overrightarrow{0}$ ceiving vincristine and adriamycin, respectively, of but rarely to the point where treatment must $\square$ be interrupted. ${ }^{24283042}$ In contrast, the episodes of severe leucopenia with frequent bacterial infection, which occurs in $50 \%$ of patients, usually necessitate longer breaks be- $\stackrel{\circ}{\mathbb{Q}}$ tween courses of chemotherapy. Moreover, the fact that most patients die either from $\frac{0}{3}$ bacterial infection and/or acute respiratory failure due to progression of pulmonary $\mathrm{Ka}-\frac{0}{0}$ posi's sarcoma suggests an indirect but major contribution of leucopenia to these fatal 을 outcomes. ${ }^{151624283036425152}$

\section{RADIATION THERAPY}

Radiation therapy has been used as palliative treatment in a small number of patients with intrathoracic Kaposi's sarcoma. ${ }^{62-65}$ Various $\frac{D}{0}$ total doses (5-35 Gy) have been used and indications have varied widely (severe haemo- N ptysis, high fever, tracheal or bronchial $N$ obstruction, respiratory symptoms refractory N to chemotherapy, and/or inability of the patient 0 to tolerate the myelosuppressive effects of chemotherapy). ${ }^{62-65}$ Improvement of symptoms and only minor complications, such as transient $\stackrel{?}{?}$ loss of appetite or malaise, are usually observed $\frac{0}{T}$ in patients who complete therapy. When precisely reported, survival was short (1-8 months). ${ }^{62-65}$ In one recent study in which $\stackrel{\square}{\square}$ whole lung irradiation fields of 10-15 Gy were? used six of 25 patients died before completing $\delta$ treatment while 16 reported subjective improvement and three did not. The average survival in this study was $12 \cdot 1$ weeks. ${ }^{65}$

\section{ASSOCIATED THERAPY}

Various associated therapies (oxygen, antipyretics, analgesics, antibiotics, and enteral or parenteral nutrition) may be required to 
improve symptoms in these patients. The role of steroids is still nuclear. On the one hand, in vitro studies suggest that they may increase the progression of Kaposi's sarcoma ${ }^{2}$ but favourable outcomes have been observed in patients with acute respiratory failure from pulmonary Kaposi's sarcoma even under controlled ventilation. ${ }^{2831}$ Moreover, in these patients steroids given with the first course of chemotherapy did not increase infections or reduce survival as in patients receiving steroids for acute respiratory failure due to Pneumocystis carinii pneumonia. ${ }^{28}$ In Kaposi's sarcoma effusion treatment is usually limited to repeated thoracocentese ${ }^{12}$ because of the lack of efficacy of chemotherapy and the inability of chest tube thoracostomy, with or without instillation of bleomycin or tetracycline, to prevent recurrence.

\section{THERAPEUTIC STRATEGIES FOR THE FUTURE}

The results currently achieved in intrathoracic Kaposi's sarcoma are disappointing. Progress may be hoped for in three different areas: (1) improved staging should be sought. Classically, staging of bronchopulmonary lung cancer is based on extension of the tumour. This is inappropriate for Kaposi's sarcoma because other factors such as immunodeficiency and non-tumour manifestations of AIDS also play a part in the choice and limits of treatment and in the outcome for the patient. ${ }^{12}$ At the present time the most appropriate classification we have is the TIS classification ( $\mathrm{T}$ : tumor extension; I: immune system; $S$ : systemic illness abnormalities), even though it was not specifically designed for intrathoracic Kaposi's sarcoma ${ }^{41}$; (2) the intervals between courses of chemotherapy could be better adhered to if the induced neutropenia could be limited by use of less toxic drugs (liposomal daunorubicin) ${ }^{6667}$ and concomitant administration of haematological growth factors. ${ }^{6869} \mathrm{New}$ trials are under way to evaluate their activity with particular attention being paid to the detection of any in vivo stimulation of HIV replication ${ }^{6869}$; and (3) improved therapeutic approaches could result from a better understanding of the physiopathological mechanisms of Kaposi's sarcoma and investigators are currently looking at manipulations of various growth factors as well as their antibodies, soluble receptors, and angiogenesis inhibitors. ${ }^{6}$

1 Mitchell D, Miller R. AIDS and the lung: update 1992. 2 Recent developments in the management of the pulmonar complications of HIV disease. Thorax 1992;47:381-90.

2 White D, Matthay R. Noninfectious pulmonary complications of infection with the human immunodeficiency virus. Am Rev Respir Dis 1989;140:1763-87.

3 Martin R, Hood A, Farmer E. Kaposi sarcoma. Medicine 1993;72:245-58.

4 Tappero J, Conant M, Wolfe S, Berger T. Kaposi's sarcoma: epidemiology, pathogenesis, histology, clinical spectrum, staging criteria and therapy. F Am Acad Dermatol 1993; 28:371-95.

5 Pitkin A, Grant A, Foley N, Miller R. Changing patterns of respiratory disease in HIV positive patients in a referral centre in the United Kingdom between 1986-7 and 1990-1. Thorax 1993;48:204-7.

6 Safai B, Schwartz J. Kaposi's sarcoma and the acquired immunodeficiency syndrome. In: De Vitta V, Hellman S, Rosenberg A, eds AIDS-Etiology, diagnosis and prevention. Rosenberg A, eds AIDS-Etiology, diagnosis

7 Pollack M, Safai B, Dupont B. HLA-DR5 and DR2 are susceptibility factors for acquired immunodeficiency syn- drome with Kaposi's sarcoma in different ethnic subpopulations. Dis Markers 1983;1:135-9.

8 Vogel J, Hinrichs S, Reynolds R, Lucin P, Jay G. The HIV tat-gene induced dermal lesions resembling Kaposi's sarcoma in transgenic mice. Nature 1988;335:606-11.

9 Ensoli B, Barillari G, Salahuddin H, Gallo R, Wong-Staal F. Tat-protein of HIV1 stimulates growth of cells derived from Kaposi's sarcoma lesions of AIDS patients. Nature 1990;345:84-6.

10 Safai B, Johnson K, Myskowski P, Koziner B, Yang SY, Cunningham-Rundles $S$, et al. The natural history of Kaposi's sarcoma in the acquired immunodeficiency syndrome. Ann Intern Med 1985;103:744-50.

11 Nakamura S, Salahuddin S, Biberferld P, Ensoli B, Markham P, Wong-Staal F, et al. Kaposi's sarcoma cells: long-term culture with growth factor from retrovirus infected CD4 + T cells. Science 1988;242:426-30.

12 Gearing D, Comeau M, Friend D, Gimpel S, Thut C, McGourty J, et al. The IL-6 signal transducer, ap130: an oncostatin receptor and affinity convector for the LIFoncostatin receptor and affinity conv

13 Nair BC, De Vico A, Nakamura S, Copeland T, Chen Y, Patel A, et al. Identification of a major growth factor for AIDS-Kaposi's sarcoma cells as oncostatin M. Science 1992;255:1430-2.

14 Ensoli B, Nakamura S, Salahuddin S, Biberfeld P, Larsan L, Beader B, et al. AIDS-Kaposi's sarcoma derived-cells express cytokines as autocrine and paracrine growth effects. Science 1989;243:223-6.

15 Garay S, Belenko M, Fazzini E, Schinella R. Pulmonary manifestations of Kaposi's sarcoma. Chest 1987;91:39-43.

16 Ognibene F, Steis R, Macher A, Liotta L, Gelma E, Pass $\mathrm{H}$, et al. Kaposi's sarcoma causing pulmonary infiltrates and respiratory failure in the acquired immunodeficiency syndrome. Ann Intern Med 1985;102:471-5.

17 Meduri G, Sover D, Lee M, Myskowski P, Caravelli J, Zaman M. Pulmonary Kaposi's sarcoma in the acquired immune deficiency syndrome. Am 7 Med 1986;81:11-18.

18 Pozniak A, Latif A, Neill P, Houston S, Chen KVR. Pulmonary Kaposi's sarcoma in Africa. Thorax 1992;47:730

19 De Truchis P, Cadranel J, Touboul JL, Denis M, Fouret P, Roux $\mathrm{P}$, et al. Fréquence respective et aspects radioRoux $P$, et al. Frequence respective et aspects radio-
cliniques de 150 pneumopathies observées chez 125 malades infectés par le virus de l'immunodéficience humaine. Presse Méd 1988;17:781-5.

20 Murray J, Felton C, Garay S, Gottlieb M, Hopewell P, Stover $\mathrm{D}$, et al. Pulmonary complications of the acquired immunodeficiency syndrome. $N$ Engl 7 Med 1984;21 1682-8.

21 Stover D, White D, Romano P, Gellene R, Robesoin W. Spectrum of pulmonary disease associated with acquired immune deficiency syndrome. Am $\mathcal{F}$ Med $1985 ; 78: 429-37$.

22 Mitchell D, Mccarty M, Fleming J, Moss F. Bronchopulmonary Kaposi's sarcoma in patients with AIDS Thorax 1992;47:726-9.

23 Cadranel J, Chouaid C, Denis M, Lebeau B, Akoun G, Mayaud C. Causes of pleural effusion in 75 HIV-infected patients. Chest 1993;104:655.

24 Gill P, Akil B, Colletti P, Rarick M, Loureiro C, BersteinSinger M, et al. Pulmonary Kaposi's sarcoma: clinical findings and results of therapy. Am $\mathcal{F}$ Med 1989;87:57-61.

25 O'Brien R, Cohn D. Serosanguineous pleural effusions in AIDS-associated Kaposi's sarcoma. Chest 1989;96:460-6.

26 Zibrak J, Silvestri R, Costello P, Marlink R, Jensen W, Robins A, et al. Bronchoscopic and radiologic features of Kaposi's sarcoma involving the respiratory system. Chest 1986;90:476-9.

27 Allier I, Cadranel J, Parquin F, Denis M, Lepen De Ven C, Antoine $\mathrm{M}$, et al. Pleurésies chez les malades infectés par le VIH. Presse Med 1991;20:1931-4.

28 Cadranel J, Kammoun S, Chevret S, Parrot A, Denis M, Winter C, et al. Results of chemotherapy in 30 AIDS patients with symptomatic pulmonary Kaposi's sarcoma. phorax 1994;49:101-3.

29 Miller R, Tomlinson M, Cottrill C, Donald J, Spittle M, Semple S. Bronchopulmonary Kaposi's sarcoma in Semple S. Bronchopulmonary Kaposi's

30 Gill P, Rarick M, Espina B, Loureiro C, Bernstein-Singer $\mathrm{M}$, Akil $\mathrm{B}$, et al. Advanced acquired immune deficiency syndrome-related Kaposi's sarcoma. Cancer 1990;65: 1074-8.

31 Fouret P, Touboul JL, Mayaud C, Akoun G, Roland J. Pulmonary Kaposi's sarcoma in patients with acquired immune deficiency syndrome: a clinicopathological study. Thorax 1987;42:262-8.

32 De Rosa G, Bara E, Guarino M, Gentile R. Multicentric Castelman's disease in association with Kaposi's sarcoma. Appl Pathol 1989;7:105-10.

33 Oksenhendler E, Duarte M, Soulier J, Cacoub P, Welker Y, Cadranel J, et al. Multicentric angiofollicular lymph node hyperplasia (Castelman's disease) associated with human

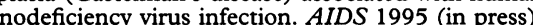

34 Khalil A, Carette M, Bazot M, Cadranel J, Mayaud C Bigot J. Intrathoracic Kaposi's sarcoma: thin CT scan findings. Eur Respir 7 1994;7:207S.

35 Sivit C, Schwartz A, Rockoff S. Kaposi's sarcoma of the

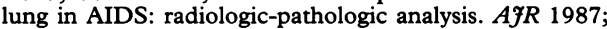
148:25-8.

36 Naidich D, Tarras M, Garay S, Birnbaum B, Rybak B, Schinella R. Kaposi's sarcoma; CT-radiographic corSchinella R. Kaposi's sarcom

37 Padovani B, Sedat J, Mouroux J, Diaine B, Chanalet S, Thyss A, et al. Sarcome de Kaposi pulmonaire chez les patients atteints du syndrome d'immunodéficience ac- 
quise. Apport de la radiographie du thorax et du scanner T Radiol 1993;74:467-72.

38 Rouffiat J, Najmark P, Sournia V. Les images radiologique du sarcome de Kaposi. Ann Radiol 1987;30:324-9.

39 Hartman T, Primack S, Müller N, Staples C. Diagnosis of thoracic complications in AIDS: accuracy of CT. $A \mathscr{F} R$ 1994;162:547-53.

40 Wolff S, Kuhlman J, Fishman E. Thoracic Kaposi's sarcoma in AIDS: CT findings. F Comput Assist Tomogr 1993;17: 60-2.

41 Krown S, Metroka C, Wernz J. Kaposi's sarcoma in the acquired immune deficiency syndrome: a proposal for uniform evaluation, response, and staging criteria. $\mathcal{f}$ Clin Oncol 1989;7:1201-7.

42 Gill P, Rarick M, McCutchan J, Slater M, Parker B, Muchmore E, et al. Systemic treatment of AIDS-related Kaposi's sarcoma: results of a randomized trial. $A m \mathcal{F} M e d 1991$; 90:427-33.

43 Hugues-Davies L, Kocjan G, Spittle M, Miller R. Occult alveolar haemorrhage in bronchopulmonary Kaposi's saralveolar haemorrhage in bronchopul

44 Mitchell D, Fleming J, Pinching A, Harris J, Moss F, Veale $\mathrm{D}$, et al. Pulmonary function in human immunodeficiency virus infection. A prospective 18-month study of serial lung function in 474 patients. Am Rev Respir Dis 1992; 146:745-51.

45 Cadranel J, Rosso J, Mayaud C, Meignan M. Radionuclide imaging in pulmonary complications of HIV infection. In: Diot P, Baulieu J, Lemarié E, eds. Nuclear medicine and Diot P, Baulieu J, Lemarie E, eds. Nuclear medicine
lung diseases. Paris: Springer-Verlag, 1993:95-104.

46 Rosso J, Guillon JM, Parrot A, Denis M, Akoun G, Mayaud $\mathrm{C}$, et al. Technetium $99 \mathrm{~m}-\mathrm{DTPA}$ aerosol and gallium-67 scanning in pulmonary complications of HIV infection. $\mathcal{F}$ Nucl Med 1992;33:81-7.

47 Woolfenden J, Carrasquillo J, Larsen S. Acquired immunodeficiency syndrome: Ga-67 citrate imaging. $\mathrm{Ra}$ diology 1987;162:383-7.

48 Lee V, Fuller J, O'Brien M. Pulmonary Kaposi's sarcoma in patients with AIDS: scintigraphic diagnosis with sequential thallium and gallium scanning. Radiology 1991;180:40912.

49 Buscombe J, Oyen W, Grant A, Claessens R, Van Der Meer $\mathrm{J}$, Cortsens $\mathrm{F}$, et al. Indium-111-labeled polyclonal human immunoglobulin: identifying focal infection in patients positive for human immunodeficiency virus. $7 \mathrm{Nucl} \mathrm{Med}$ 1993;34:1621-5.

50 Khalil A, Carette M, Cadranel J, Mayaud C, Akoun G, Bigot $\mathrm{J}$. Magnetic resonance imaging findings in pulmonary Kaposi's sarcoma: a series of 10 cases. Eur Respir f 1994 7:1285-9.

51 Gelmann E, Longo D, Lane H, Fauci A, Masur H, Wesley $\mathrm{M}$, et al. Combination chemotherapy of disseminated Kaposi's sarcoma in patients with the acquired immune deficiency syndrome. Am ₹ Med 1987;82:456-62.

52 Laubenstein L, Krigel R, Odajnyk C, Hymes K, FriedmanKien A, Wernz J, et al. Treatment of epidemic Kaposi's sarcoma with etoposide or a combination of doxorubicin sarcoma with etoposide or a combination of doxorubicin,
bleomycin, and vinblastin. $\mathcal{F}$ Clin Oncol 1984;2: bleomycin
53 Hirsch M, D'aquilla $R$. Therapy for human immunodeficiency virus infection. $N$ Engl $\mathcal{f}$ Med 1993;328 1686-95.

54 Masur H. Prevention and treatment of pneumocystis pneumonia. N Engl fु Med 1993;327:1853-60.

55 Girard PM, Landman R, Gaudebout C, Olivares R, Saimo A, Jelazko P, et al. Dapsone-pyremethamine compared with aerosolized pentamidine as primary prophylaxis against Pneumocystis carinii pneumonia and toxoplasmosis in HIV infection. $N$ Engl $\mathcal{F}$ Med 1993;328:1514-20.

56 Slavin M, Hoy J, Stewart K, Pettinger M, Lucas CR, Ken $S$, et al. Oral dapsone versus nebulized pentamidine for Pneumocystis carinii pneumonia prophylaxis: an open ranPneumocystis carinii pneumonia prophylaxis: an open randomized prospective trial to assess efficacy and haematological toxicity. AIDS 1992;6:1169-74

57 Lane H, Falloon J, Walker R, Deyton L, Falloon J, Walker $\mathrm{RE}$, et al. Zidovudine in patients with HIV infection and Kaposi's sarcoma. Ann Intern Med 1989;111:41-50.

58 Rarick M, Gill P, Montgomery T, Bernstein-Singer M, Jones B, Levine A, et al. Treatment of epidemic Kaposi's sarcoma with combination chemotherapy (vincristine and ble- $C$ omycin) and zidovudine. Ann Oncol 1990;1:147-9.

59 Shepherd F, Evans W, Garvey B, Read S, Klein M, Fanning $\mathrm{M}$, et al. Combination chemotherapy and interferon in $\overrightarrow{0}$ the treatment of Kaposi's sarcoma associated with the acquired immunodeficiency syndrome. Can Med Assoc $\mathcal{F}$ 1988;139:635-9.

60 Krigel R, Slywotzky C, Lonberg M, Greene M, Andes R, Kempf $\mathbf{R}$, et al. Treatment of epidemic Kaposi's sarcoma with a combination of interferon-alpha $2 b$ and etoposide. f Biol Response Mod 1988;7:359-64.

61 Caumes E, Guermonprez G, Katlama C, Gentilini M. AIDS associated mucocutaneous Kaposi's sarcoma treated with bleomycin. AIDS 1992;6:1483-7.

62 Bach M, Bagwell S, Fanning J. Primary pulmonary Kaposi's sarcoma in the acquired immunodeficiency syndrome: a $\mathrm{O}$ cause of persistent pyrexia. Am f Med 1988;85:275-281.

63 Berson A, Quivey J, Harris J, Warra J. Radiation therapy for AIDS-related Kaposi's sarcoma. Int $\mathcal{f}$ Radiat Oncol Biol Phys 1990;19:569-75.

64 Doyle M, Johnstone P, Watkins E. Role of radiation therapy in management of pulmonary Kaposi's sarcoma. South Med f 1993;86:285-8.

65 Meyer J. Whole-lung irradiation for Kaposi's sarcoma. $A m$ of f Clin Oncol 1993;16:372-6.

66 Presant CA, Scolaro M, Kennedy P, Blayney D, Flanagan B, LisakJ, et al. Liposomal daunorubicin treatment of HIVassociated Kaposi's sarcoma. Lancet 1993;341:1242-3.

67 Schürman D, Dormann T, Grünewald T, Ruf B. Successful treatment of AIDS-related pulmonary Kaposi's sarcoma with liposomal daunorubicin. Eur Respir f 1994;7:824-5.

68 Gill P, Bernstein-Singer M, Espina B, Rarick M, Magy F, Montgomery $\mathrm{T}$, et al. Adriamycin, bleomycin and vincristine chemotherapy with recombinant granulocytemacrophage colony-stimulating factor for the treatment of AIDS-rat Kaposi's sarcoma. AIDS 1992;6:147"

Sloand E, Kumar P, Pierce P. Chemotherapy for patients pulmonary Kaposi's: benefit of filgrastim (G-CSF) in supporting dose administration. South Med f 1993;86: 1219-24. 